\title{
Numerical Investigation of the Effect of Baffle Inclination Angle on Nanofluid Natural Convection Heat Transfer in A Square Enclosure
}

\author{
Barik AL-Muhja ${ }^{a}$ and Khaled Al-Farhany ${ }^{a *}$ \\ ${ }^{a}$ Department of mechanical engineering, University of Al-Qadisiyah, Al-Qadisiyah, Iraq.
}

\begin{tabular}{l} 
A R T I C L E I N \\
\hline Article history: \\
Received 02 May 20 \\
Received in revised \\
Accepted 28 June 20 \\
\hline Keywords: \\
Natural convection \\
Nanofluid \\
Baffle \\
Conjugate \\
Inclined angle
\end{tabular}

Inclined angle

\begin{abstract}
A B S T R A C T
The characteristics of the conjugate natural convection of $\left(\mathrm{Al}_{2} \mathrm{O}_{3}\right.$-water) nanofluid inside differentially heated enclosure are numerically analyzed using COMSOL Multiphysics (5.3a). The enclosure consists of two vertical walls, the left wall has a thickness and maintain at a uniform hot temperature, while the opposite wall at cold temperature and the horizontal walls are isolated. A high thermal conductivity thin baffle has been added on the insulated bottom wall at a different inclination angles. The effect of the volume fractions of nanoparticles $(\phi)$, Rayleigh number $(\mathrm{Ra})$, solid wall thermal conductivity ratio $(\mathrm{Kr})$, baffle incline angles $(\varnothing)$ and the thickness of solid wall (D) on the isothermal lines, fluid flow patterns and the average Nusselt number $(\mathrm{Nu})$ has been investigated. At low Rayleigh number $\left(\mathrm{Ra}=10^{3}\right.$ to $\left.10^{4}\right)$ the Isothermal lines are parallel with the vertical wall which is characteristic of conduction heat transfer. On the other hand, when Rayleigh number increase to $\left(\mathrm{Ra}=10^{6}\right)$, the isotherms lines distribution in the inner fluid become parallel curves with the adiabatic horizontal walls of the enclosure and smooth so convection heat transfer becomes dominant. As the Rayleigh number further increases, the average Nusselt number enhance because of buoyancy force become stronger. In addition, the fluid flow within the space is affected by the presence of baffle, its causes blockage and obstruction of flow near the hot wall. The maximum value of the stream function can be noticed in case of nanofluid when the angle is in rang $(30<\varnothing \leq 60)$, therefore, the maximum value of $(\mathrm{Nu})$ find in this range whereas they decrease when the angle is in rang $(60>\varnothing \geq 90)$ where the baffle obstruction causing decreases in flow movement. As a result, the left region temperature increase and accompanied with a minimum $(\mathrm{Nu})$, This is an indication of reduction in the heat transfer. In addition, when the inclination angle increases $(\varnothing>90)$, the baffle obstruction on flow and fluid resistance becomes smaller and the buoyancy strength increase, as a result, the heat transfer is increasing again in this case. The results shown, the improvement rate in the $(\mathrm{Nu})$ between the highest obstruction occurs at the angle $(\varnothing=90)$ and the least obstruction at $(\varnothing=30)$ is about $(7 \%)$. The increasing of wall thickness from $(D=0.1$ to 0.4$)$ leads to reduce the intensive heating through the solid wall as well as small heat transferred to the inner fluid.
\end{abstract}

\section{Introduction}

The heat transfer by natural convection was widely used as an efficient heat dissipation means in modern industry as a result of technological evolution. It was used in nuclear reactor cooling systems and electronic devices such as high-speed computer processors, auxiliary systems in solar collectors, and also used in many applications of the agricultural industries.
There are several important engineering applications of natural convection were vertical surfaces, square and various geometry of enclosure filled with working fluid. The wide number of thermal applications related to convection heat transfer using a fluid medium drawn the researchers to improve the properties of those conventional fluids.

* Corresponding author.

E-mail address: khaled.alfarhany@qu.edu.iq (Khaled AL-Farhany) 


\begin{tabular}{|c|c|c|c|}
\hline \multicolumn{4}{|c|}{ Nomenclature } \\
\hline$C p$ & specific heat $\left(\mathrm{J} \mathrm{kg}^{-1} \mathrm{~K}^{-1}\right)$ & \multicolumn{2}{|c|}{ Greek symbols } \\
\hline$g$ & gravitational acceleration $\left(\mathrm{m} \mathrm{s}^{-2}\right)$ & $\alpha$ & thermal diffusivity $\left(\mathrm{m}^{2} \mathrm{~s}^{-1}\right)$ \\
\hline$k$ & thermal conductivity $\left(\mathrm{W} \mathrm{m}{ }^{-1} \mathrm{~K}^{-1}\right)$ & $\beta$ & thermal expansion coefficient $\left(\mathrm{K}^{-1}\right)$ \\
\hline$k r$ & thermal conductivity ratio, $\mathrm{kr}=\mathrm{kw} / \mathrm{kf}$ & $\phi$ & solid volume fraction \\
\hline$L$ & length of the enclosure (m) & $\Theta$ & dimensionless temperature \\
\hline$L b$ & baffle length (m) & $\varnothing$ & baffle inclination angle \\
\hline $\mathrm{Nul}$ & local Nusselt number along with the heat source & $\mu$ & dynamic viscosity $\left(\mathrm{kg} \mathrm{m}^{-1} \mathrm{~s}^{-1}\right)$ \\
\hline $\mathrm{Nu}$ & average Nusselt number & & \\
\hline$p$ & pressure $\left(\mathrm{kg} \mathrm{m}^{-1} \mathrm{~s}^{-2}\right)$ & \multicolumn{2}{|c|}{ Subscripts } \\
\hline$P$ & non-dimensional pressure & av & average \\
\hline $\operatorname{Pr}$ & Prandtl number & $\mathrm{b}$ & baffle \\
\hline$R a$ & Rayleigh number & $\mathrm{c}$ & cold \\
\hline$T$ & dimensional temperature & $\mathrm{f}$ & fluid (pure water) \\
\hline$U$ & non-dimensional velocity component $\mathrm{X}$-direction & $\mathrm{h}$ & hot \\
\hline$V$ & non-dimensional velocity components Y-direction & $\mathrm{nf}$ & nanofluid \\
\hline$w b$ & baffle width $(\mathrm{m})$ & $\mathrm{p}$ & nanoparticle \\
\hline$X$ & non-dimensional X-coordinates & $\mathrm{s}$ & solid \\
\hline$Y$ & non-dimensional Y-coordinates & w & wall \\
\hline
\end{tabular}

By comparison, the heat transfer coefficient in the forced convection is greater than that of the natural convection means of heat dissipation. Therefore, more investigations and conducts should be experiments as attempts to improve the efficiency of heat transfer through natural convection with close volume (enclosure) constraints. The thermal properties of the conventional working fluid could be enhanced by dispersing solid nanoparticle, which increases the thermal efficiency of the engineering device. also, it is a bright idea behind the creative design of equipment that operates by the natural convection Choi and Eastman [1]. Natural convection in an enclosure filled with air with vertical walls that are differentially heated, while its horizontal walls are adiabatic has had been studied extensively, some of these studies [2-5]. A great number of studies, square, rectangular, inclined enclosure use of nanofluid as working media for various wall conditions and zero thickness wall has been studied extensively by researchers, some of these studies presented by [6-13]. Also, a wide number of studies has received some consideration in recent years for the heat transfer modulation in cavities owing to the introduction of obstacles and baffles fixed to the wall and the cavity filled with air and its wall have different boundary condition was presented by [14-24]. A numerical study of natural convection in a cavity in the case of a baffle attached to one of its walls and differentially heated vertical and filled with nanofluid was performed by Mahmoudi et al. [25]. They studied numerically the natural convection in a square cavity filled with $(\mathrm{Cu}$-water $)$ nanofluid. A horizontal heat source partition with a constant heat flux was attached to the left wall of the cavity. The effects of the heat source geometry; position $(\mathrm{Db})$, solid volume fraction $(\phi)$ and Rayleigh number (Ra) were considered. It was found that the increase in volume fraction $(\phi)$ was accompanied by an increase in the average Nusselt number while it decreased by increasing (Lb). In addition, it was found that when (Ra) increased, the heater source temperature was decreased. Habibzadeh et al. [26] conclude a numerical study of the natural convection of a square enclosure filled with $\left(\mathrm{Al}_{2} \mathrm{O}_{3}\right.$-water) nanofluid. An adiabatic partition set on the hot bottom wall of the cavity. The influences of various parameters were studied. It was presented that the increasing of ( $\mathrm{Ra})$ cause an increase in average Nusselt number while; it was not sensitive to $(\phi)$. Also, it was found that when the partition height was increased, the rate of heat transfer was decreased. Sayehvand et al. [27] studied numerically the natural convection in a square cavity filled with $\left(\mathrm{Al}_{2} \mathrm{O}_{3}\right.$-water $)$ nanofluid. Two adiabatic partitions were attached symmetrically at the horizontal walls of the cavity.
They concluded that the Nusselt number was increased by increasing (Ra) while it decreased by increasing ( $\mathrm{Lb}$ ). In addition, they found that by increasing (Lb), the vortices moved towards the vertical walls. Naoufal, et al. [28] studied numerically the natural convection in a square cavity filled with [Cu-water] nanofluid. A hot partition was attached vertically to the bottom wall of the cavity. The effects of the partition length (Lb), location $(\mathrm{Db})$, were considered. It was present that for all $(\phi)$ the average Nusselt number was going up by increasing (Ra). Also, it was found that the maximum average Nusselt number occurred as the partition was located at the center of the cavity. Selimefendigil and Oztop [29] investigated numerically the natural convection in an inclined square cavity filled with different nanofluids $\left(\mathrm{Al}_{2} \mathrm{O}_{3}\right.$-water and $\mathrm{CuO}$-water $)$. A high conductive partition was divided equally the space of cavity. It was concluded that the average Nusselt number was increased with increasing $(\mathrm{Gr})$ and $(\phi)$ while, it decreased by increasing (Db).Not long ago, the Conjugate natural convection heat transfer inside an enclosure which exposes to different boundary conditions and finite wall thickness has been received a notably large in size by many studies because of its importance to many engineering systems. Costa et al.[30] investigated numerically the conjugate natural convection in an enclosure with rectangular partitions of finite thickness. The position, length and thermal conductivity of the partitions are varied. Mobedi [31] studied numerically the conjugate natural convection in an inclined square enclosure filled with air, which consists of negligible wall thickness with and uniform heat distribution. It was concluded that the heat transfer between the wall and inner fluid (solid-fluid) interface increase with the increase of $(\mathrm{Ra})$ number and thermal conductivity ratio (kr). Also, found that the temperature gradients through the cavity have small effects by the horizontal wall. Basak et al. [32] study numerically the conjugate natural convection in a square enclosure filled with air. The square cavity consists of vertical differentially heated conducting walls of definite wall thickness (t1 and $\mathrm{t} 2$ ) and adiabatic horizontal walls. It was concluded that for (case 2) ; as Rayleigh number increases, the temperature gradient across the cavity in the inner fluid was decreasing with the two wall thicknesses. Also found that an increase in $(\mathrm{K})$ results in Strengthening the flow circulation cells due to increase the heat intensive to the fluid and note that not taking the (Pr), location and thickness of the solid walls into account. Alsabery, Chamkha et al. [33] investigated numerically the conjugate natural convection in a square enclosure filled with $\left(\mathrm{Al}_{2} \mathrm{O}_{3}\right.$-water, $\mathrm{Cu}$-water, Ag-water, and TiO2-water) nanofluids. The cavity consists of two 
horizontal walls, which have sinusoidal temperature distributions, while the two vertical walls were kept adiabatic. As the solid wall thickness enlarge, the heat convection rate was significantly improved. Also found the increment in Phase deviation have effects on the temperature distribution, fluid flow behavior across the cavity and Nusselt number were significantly enhanced. Chamkha and Ismael [34] studied the conjugate natural convection in a porous medium enclosure using nanofluids as a working fluid. The cavity triangular thick wall, where the heat was supplied. It was shown that at low Rayleigh number the heat transfer was significantly enhanced with increasing the volume fraction of the solid particles

At a recent time, Al-Farhany and Abdulkadhim [35] analyzed the effect of conjugate natural convection in a square a porous enclosure with a partially heated vertical wall and the horizontal wall kept adiabatic. They demonstrate that by increasing Rayleigh number (Ra) and the thermal conductivity ratio of the solid wall, the heat transfer rate also increased. Ishrat and Alim [36] Studied numerically the effect of the conjugate on the fluid flow and heat convection inside a vertical cavity with heat conducting vertical wall, the cavity filled with ( $\mathrm{Cu}$-water) nanofluid as a working fluid. The vertical thick wall of cavity exposed to a constant and uniform distribution heat flux and a moveable divider was attached at the bottom horizontal wall of it. It is found that the location of the divider contributes to enhancing the rate of convection heat transfer.

Based on the above literature reviews, notwithstanding the numerous studies have been done numerically on natural convection heat transfer of nanofluids within a rectangular and square cavities at different boundary conditions were exposed to its walls with and without baffle. But there is a few information on conjugate natural convection nanofluids with single thin baffle attached on the adiabatic horizontal wall with inclined angle. This issue might exist in a number of engineering applications such as solar collectors, heat exchangers, and cooling of electronic equipment using nanofluids.

In this study, A numerical analysis was performed to study the effect of conjugate heat transfer of $\left(\mathrm{Al}_{2} \mathrm{O}_{3}\right.$ - water $)$ nanofluid inside an enclosure have aspect ratio equal to unity. The high conductivity single baffle mounted on adiabatic horizontal wall of enclosure with different inclined angle $(\varnothing)$. The enclosure has a thick left hot wall while the opposite one is at uniform cold temperature while the other walls are adiabatic. Numerical results are obtained by using COMSOL Multiphysics software. Also investigating the effects of Rayleigh number (Ra), Solid volume fraction of the nanoparticles $(\phi)$, and Inclined angle of baffle $(\varnothing)$ on natural convection heat transfer nanofluids inside a square cavity. Finally, the results is presented in the form of stream function contour, isotherms pattern and the value of average Nusselt number.

\section{Mathematical Modelling}

Fig. 1 presents the coordinate systems and a square enclosure. The horizontal walls of the enclosure are kept insulated, while the right vertical wall is maintained at uniform cold temperature and the vertical left wall has an effective thickness wall equal to $(\mathrm{D}=0.1)$ and the other enclosure walls are assumed to be without thicknesses. The free space between walls enclosure is filled with the Nanofluid, which is assumed to be incompressible flow. The thermophysical properties of the fluid and nanoparticles are given in Table 1. A high conducting baffle has a length $(\mathrm{Lb}=0.3)$ and the baffle width $(\mathrm{Wb}=0.02)$. The baffle is attached to the horizontal adiabatic bottom wall with a different inclination angle $(\varnothing)$. The flow is controlled by buoyancy force. The density variations are illustrated by the Boussinesq approximation to simplify the solution procedure.

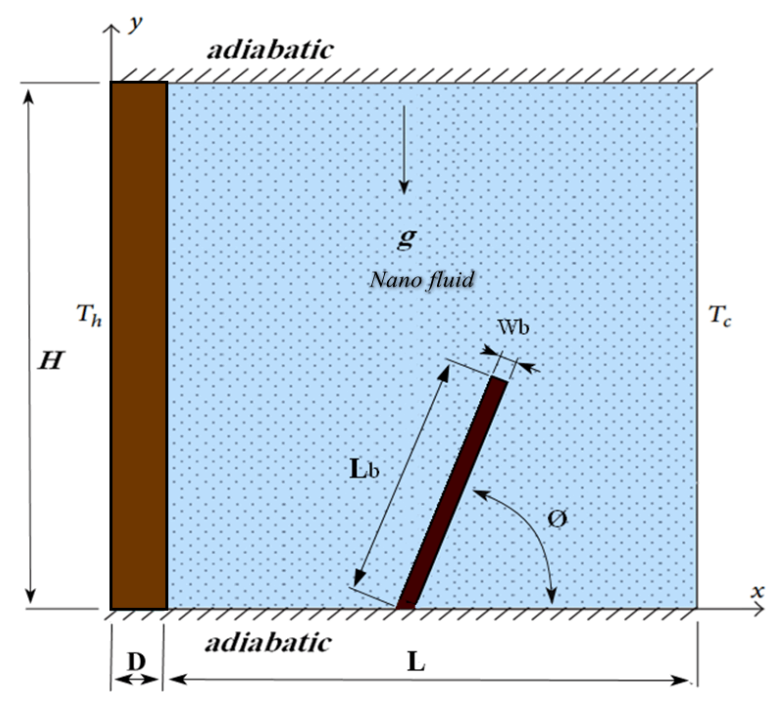

Figure 1. Scheme of the model

Table 1. Thermal physical-properties of fluid and $\left(\mathrm{Al}_{2} \mathrm{O}_{3}\right)$ Nanoparticles at $\mathbf{T}=25^{\circ} \mathrm{c}$ [27].

\begin{tabular}{lll}
\hline Properties & Pure water & $\mathbf{A l}_{\mathbf{2}} \mathbf{O}_{\mathbf{3}}$ \\
\hline $\mathrm{Cp}(\mathrm{J} / \mathrm{kg} \mathrm{K})$ & 4179 & 765 \\
$\mathrm{P}\left(\mathrm{kg} / \mathrm{m}^{3}\right)$ & 997.1 & 3970 \\
$\mathrm{k}(\mathrm{W} / \mathrm{m} \mathrm{K})$ & 0.613 & 40 \\
$\beta(1 / \mathrm{K})$ & $21 \times 10^{-5}$ & $0.85 \times 10^{-5}$ \\
\hline
\end{tabular}

\subsection{Assumption:-}

The mathematical equations describing the physical model are based on the following assumptions:-

1- The thermophysical properties are constant except for the density in the buoyancy force (Boussinesq's hypothesis).

2- The fluid phase and nanoparticles are in a thermal equilibrium state.

3- Nanoparticles are spherical.

4- Internal heat generation is neglected.

\subsection{The Equation of the conservation:-}

In the present work, the two-dimensional governing equations in cartesian coordinate for natural convection of a nanofluid in a square enclosure with single baffle mount on the adiabatic wall and laminar, incompressible flow are presented. The governing equations in the dimensional form used in the present study given by [10]:

\section{Conservation of mass:-}

The transport of a conserved quantity given by:

$$
\frac{\partial u}{\partial x}+\frac{\partial v}{\partial y}=0
$$

\section{Conservation of Momentum:-}

Momentum equation includes two components, which can be written as follows:-

$\mathrm{x}$ - Component of the momentum equation:- 
$\rho_{n f}\left(u \frac{\partial u}{\partial x}+v \frac{\partial u}{\partial y}\right)=-\frac{\partial p}{\partial x}+\mu_{n f}\left(\frac{\partial^{2} u}{\partial x^{2}}+\frac{\partial^{2} u}{\partial y^{2}}\right)$

$\mathrm{y}$ - Component of the momentum equation:-

$\rho_{n f}\left(u \frac{\partial v}{\partial x}+v \frac{\partial v}{\partial y}\right)=-\frac{\partial p}{\partial y}+\mu_{n f}\left(\frac{\partial^{2} v}{\partial x^{2}}+\frac{\partial^{2} v}{\partial y^{2}}\right)+g(\rho \beta)_{n f}\left(T-T_{c}\right)$

\section{Energy equation:}

(3)

A- For the fluid region.

The energy equation for the nanofluid inside the enclosure is given by:

$u \frac{\partial T}{\partial x}+v \frac{\partial T}{\partial y}=\alpha_{n f}\left(\frac{\partial^{2} T}{\partial x^{2}}+\frac{\partial^{2} T}{\partial y^{2}}\right)$

B- For the solid region.

The energy equation of the wall and the baffle is written as [33]

$\frac{\partial^{2} T}{\partial x^{2}}+\frac{\partial^{2} T}{\partial y^{2}}=0$

No fluid motion inside the solid region (baffle).

where $u$ and $v$ are the velocity components in the $x$ and $y$-directions, respectively. $p$ is the pressure, $T$ is the temperature, and $\beta$ is the thermal expansion coefficient.

The following dimensionless parameters are used to obtain the dimensionless form of the governing equations:-

$$
\begin{aligned}
& \mathrm{Y}=\frac{\mathrm{y}}{\mathrm{L}}, \mathrm{X}=\frac{\mathrm{x}}{\mathrm{L}}, \quad \mathrm{U}=\frac{\mathrm{uL}}{\alpha_{\mathrm{f}}}, \mathrm{V}=\frac{\mathrm{vL}}{\alpha_{\mathrm{f}}}, \Delta \mathrm{T}=(\mathrm{Th}-\mathrm{Tc}), \theta=\frac{\mathrm{T}-\mathrm{Tc}}{\Delta \mathrm{T}}, \\
& \operatorname{Pr}=\frac{v_{\mathrm{f}}}{\alpha_{\mathrm{f}}}, \mathrm{P}=\frac{p L^{2}}{\rho_{n f} \alpha_{f}^{2}}, \mathrm{Ra}=\frac{g \beta_{f} \Delta T L^{3}}{v_{f} \alpha_{f}} .
\end{aligned}
$$

The above governing equations are written in the following dimensionless form:

$$
\begin{aligned}
& \frac{\partial U}{\partial X}+\frac{\partial V}{\partial Y}=0 \\
& U \frac{\partial U}{\partial X}+V \frac{\partial U}{\partial Y}=-\frac{\partial P}{\partial X}+\frac{v_{n f}}{v_{f}} \operatorname{Pr} \cdot\left(\frac{\partial^{2} U}{\partial X^{2}}+\frac{\partial^{2} U}{\partial Y^{2}}\right) \\
& U \frac{\partial V}{\partial X}+V \frac{\partial V}{\partial Y}=-\frac{\partial P}{\partial Y}+\frac{v_{n f}}{v_{f}} \operatorname{Pr} \cdot\left(\frac{\partial^{2} V}{\partial X^{2}}+\frac{\partial^{2} V}{\partial Y^{2}}\right) \\
& +\operatorname{Ra} \cdot \operatorname{Pr} \cdot \frac{(\rho \beta)_{\mathrm{nf}}}{\rho_{n f} \beta_{f}} \theta \\
& U \frac{\partial \theta}{\partial X}+V \frac{\partial \theta}{\partial Y}=\frac{\alpha_{n f}}{\alpha_{f}}\left(\frac{\partial^{2} \theta}{\partial X^{2}}+\frac{\partial^{2} \theta}{\partial Y^{2}}\right) \\
& \frac{\partial^{2} \theta}{\partial X^{2}}+\frac{\partial^{2} \theta}{\partial Y^{2}}=0
\end{aligned}
$$

\subsection{Nanofluid Thermophysical properties:}

The thermo-physical properties of the nanofluid are obtained from the following relations [7].

The thermal diffusivity and the effective density of the nanofluid are given by:

$$
\alpha_{\mathrm{nf}}=\frac{k_{\mathrm{nf}}}{\left(\rho C_{p}\right)_{\mathrm{nf}}}
$$

$$
\rho_{\mathrm{nf}}=(1-\phi) \rho_{\mathrm{f}}+\phi \rho_{\mathrm{s}}
$$

The heat capacitance and the thermal expansion coefficient of the nanofluid are defined as

$$
\begin{aligned}
& \left(\rho C_{p}\right)_{\mathrm{nf}}=(1-\phi)\left(\rho C_{p}\right)_{\mathrm{f}}+\phi\left(\rho C_{p}\right)_{\mathrm{s}} \\
& (\rho \beta)_{\mathrm{nf}}=(1-\phi)(\rho \beta)_{\mathrm{f}}+\phi(\rho \beta)_{\mathrm{s}}
\end{aligned}
$$

The viscosity of the nanofluid estimated, using the Brinkman model, is given by:

$\mu_{\mathrm{nf}}=\frac{\mu_{\mathrm{f}}}{(1-\phi)^{2.5}}$

The effective thermal conductivity of the nanofluid is estimated Maxwell model as:

$\frac{k_{\mathrm{nf}}}{k_{\mathrm{f}}}=\frac{k_{\mathrm{s}}+2 k_{\mathrm{f}}-2 \phi\left(k_{\mathrm{f}}-k_{\mathrm{s}}\right)}{k_{\mathrm{s}}+2 k_{\mathrm{f}}+2 \phi\left(k_{\mathrm{f}}-k_{\mathrm{s}}\right)}$

\subsection{Local Nusselt number}

In order to investigate the effects of different parameters on heat transfer, the local Nusselt number at the wall is written as [7]:-

$$
\mathrm{Nu}_{1}=-\left.\left(\frac{k_{\mathrm{nf}}}{k_{f}}\right) \cdot \frac{\partial \theta}{\partial X}\right|_{x=D}
$$

the average Nusselt number at the solid wall as

$$
\mathrm{Nu}_{\mathrm{av}}=-\left.\left(\frac{k_{\mathrm{nf}}}{k_{f}}\right) \cdot \int_{0}^{H} \frac{\partial \theta}{\partial X} \cdot d y\right|_{x=D}
$$

\subsection{Boundary conditions}

The dimensionless boundary conditions are as shown in Table 2 .

Table 2. Dimensionless boundary conditions

\begin{tabular}{lll}
\hline Location & Boundary conditions & comments \\
\hline $\mathrm{X}=0$ & $\mathrm{U}=\mathrm{V}=0 ; \theta(y)=1$ & vertical left wall \\
$\mathrm{X}=1$ & $\mathrm{U}=\mathrm{V}=0 ; \theta(y)=\mathrm{O}$ & vertical right wall \\
$\mathrm{Y}=0,1$ & $\mathrm{U}=\mathrm{V}=0 ; \partial \theta / \partial Y=0$ & Horizontal wall \\
$\begin{array}{l}\text { At the fluid to } \\
\text { solid interfaces }\end{array}$ & $\mathrm{U}=\mathrm{V}=0: \frac{\partial \theta}{\partial X}{ }_{n f}=K_{r} \frac{\partial \theta}{\partial X}$ fluid to solid $_{\text {solid }}$ & interfaces \\
$\begin{array}{l}\text { At Baffle Left } \\
\text { and right surfaces }\end{array}$ & $\mathrm{U}=\mathrm{V}=0 ;\left.\frac{\partial \theta}{\partial X}\right|_{\text {baffle }}=\left.\mathrm{k}_{\mathrm{r}} \frac{\partial \theta}{\partial X}\right|_{\mathrm{nf}}$ & \\
$\begin{array}{l}\text { Upper surface } \\
\text { Un }\end{array}$ & $\mathrm{U}=\mathrm{V}=0 ;\left.\frac{\partial \theta}{\partial Y}\right|_{\text {baffle }}=\left.\mathrm{k}_{\mathrm{r}} \frac{\partial \theta}{\partial Y}\right|_{\mathrm{nf}}$ & \\
\hline
\end{tabular}

\section{Numerical Solutions:}

In present work, the COMSOL Multiphysics (5.3a) CFD software package is used to solve the non-dimensional governing equations. The COMSOL Multiphysics is a finite element analysis, solver, and simulation software package. The Incompressible Naiver-Stokes application mode (laminar fluid flow), the Convection-Conduction application mode (cc), and the heat transfer in the fluid are used for equations (8), (9), and (10), respectively. Also, the convergence criterion error is set to $10^{-6}$. Galerkin's method provides a powerful numerical solution to differential equations and modal analysis. Fig. 2 shows a two-dimensional computational domain in a cartesian coordinate system which is sub-divided into a number of a small element due to the triangle mesh. The purpose of checking the grid size sensitivity is to obtain high accuracy solution and reduce the calculation time with minimum elements number this means to obtain the grid 
independent solution. Table 3. Shows the influence number of elements (mesh size) on the average Nusselt number in case of the vertical baffle at $\left(\mathrm{Ra}=10^{5}\right)$ and $(\mathrm{Kr}=1)$. The average Nusselt number at a mesh size of (9423) have very small deviation with that results obtained for the other mesh size. Therefore, finer mesh size has been selected for all cases in this study.

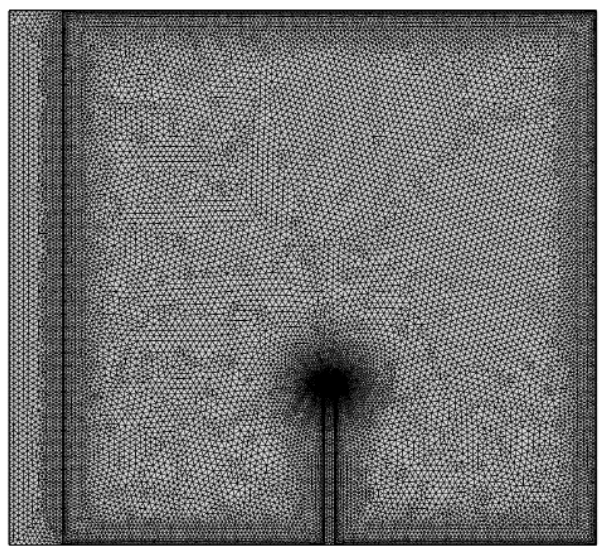

Figure 2. The triangle mesh Distribution of the enclosure.

\subsection{Validation}

In order to check the accuracy of the code for enclosure filled with a nanofluid model and in the present of baffle studies. The numerical solution relates to the heat transfer and fluid flow inside a differently heated square enclosure is further validated by comparing the present results against the numerical simulation results of Basak and Chamkha [12] for $\mathrm{Ra}=\left(10^{5}\right)$ and volume fraction $(\phi=0.2)$. It is clear that the present code is agreed well with other work reported in the literature as shown in Fig. 3.

Present results

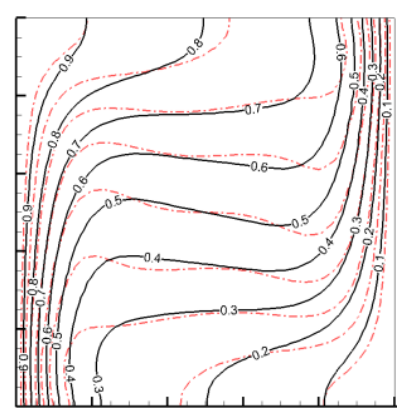

$\theta$

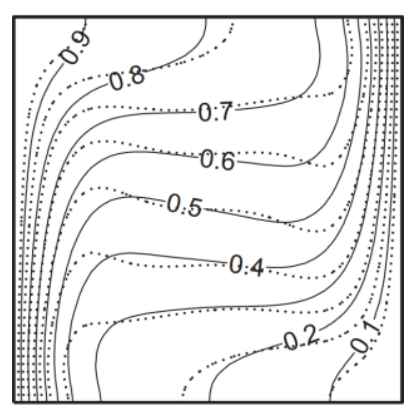

$\psi$
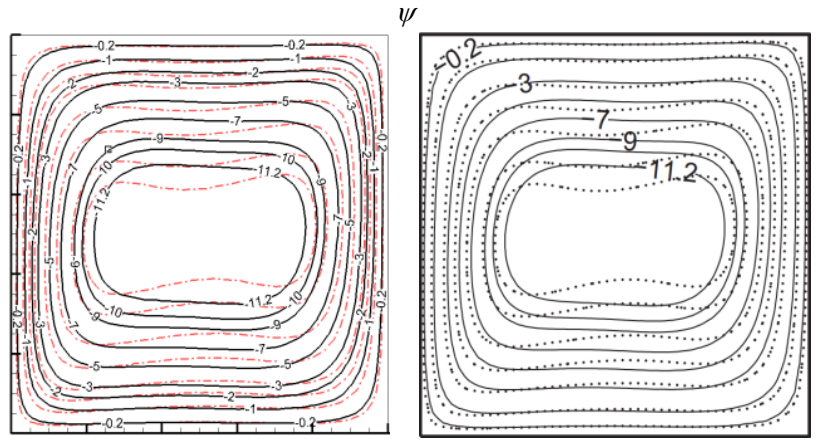

Figure 3. Comparison of the Isothermal lines, stream function contours for $\mathrm{Cu}-$ Water nanofluids for $(\mathrm{Ra})=105$ and $\phi=0.2$..., water and -, nanofluid.
Table 3. Shows the relation between the average Nusselt number $(\mathrm{Nu})$ along with left sidewall square enclosure and the number of elements used for $\left(\operatorname{Ra}=10^{5}\right),(D=0.1)$ and $(K r=1)$.

\begin{tabular}{lcc}
\hline size of Mesh & Mesh elements & Average Nusselt number \\
\hline Coarse & 1630 & 3.2758 \\
Normal & 2300 & 3.2747 \\
Fine & 3320 & 3.2684 \\
Finer & 9423 & 3.2684 \\
Extra fine & 24308 & 3.2683 \\
Extremely fine & 34022 & 3.2682 \\
\hline
\end{tabular}

\section{Results}

The natural convection heat transfer and fluid flow inside the enclosure filled with $\left(\mathrm{Al}_{2} \mathrm{O}_{3}\right.$-water) nanofluid and an inclined baffle attached to the bottom horizontal is investigated numerically.

The enclosure has adiabatic horizontal walls while the left sidewall of the enclosure is solid and heat conducting with finite thickness and conductivity, while the vertical right wall is maintained at cold temperature. The present investigation is performed in the following range of the parameter, Rayleigh number (Ra), solid volume fraction of nanoparticles $(\phi)$, thermal conductivity ratio $(\mathrm{Kr})$ of the solid wall, thickness of hot thick wall (D) and baffle incline angles(Ø), and show their influence on the stream function and isotherms patterns. The values of Rayleigh numbers are $\left(\mathrm{Ra}=10^{3}, 10^{4}, 10^{5}\right.$ and $\left.10^{6}\right)$, solid volume fraction of nanoparticles considered are $(\phi=0,0.02,0.04$ and 0.06$)$, solid wall thermal conductivity ratio $(\mathrm{Kr}=0.1,1$ and 10$)$, thickness of hot solid wall $(\mathrm{D}=0.1,0.2,0.3$ and $0.4)$ and baffle incline angles $(\varnothing=30,60,90,120$, and 150). The baffle dimension in this study are $(\mathrm{Lb}=0.3)$ and thickness ( $w b=0.02)$ which stay constant for all cases.

\subsection{Effect of Rayleigh number.}

Fig. 4. Illustrates the effects of Rayleigh number (Ra) of rang $\left(10^{3}\right.$ to $\left.10^{6}\right)$ and the nanoparticles volume fraction of $\left(\mathrm{Al}_{2} \mathrm{O}_{3}\right.$-water $)$ with $(\phi=0.06)$ when $(\mathrm{Kr}=1),(\mathrm{D}=0.2)$ and $(\varnothing=90)$, upon stream function and isotherms contours in the square enclosure in presence of the vertical baffle. The left two columns show the stream function and the right two columns shows the isotherm for pure fluid and nanofluid respectively.

From the right two columns, it can be seen that the Isothermal line at low Rayleigh number $\left(\mathrm{Ra}=10^{3}\right.$ and $\left.10^{4}\right)$ are parallel with the vertical walls of the enclosure for all range of the solid volume fraction of the nanofluid which is characteristic of conduction heat transfer. When increasing Rayleigh number to $\left(\mathrm{Ra}=10^{6}\right)$, isotherms line distribution in the inner fluid become parallel curves with the adiabatic horizontal walls of the enclosure and smooth, in this case, convection heat transfer becomes dominant. As the Rayleigh number further increases, the natural convection enhanced because of buoyancy force become stronger. In addition, fluid flow strengths are influenced by the presence of nanoparticle. When increasing the nanoparticles volume fraction $(\phi)$, the flow strength and buoyancy force increasing. In addition to the effect of increase Rayleigh number (Ra), causing decreases temperatures of the hot wall this was an indication of heat transfer enhancement by the fluid. It can be seen that the wall temperature decreases from 0.8 for $(\mathrm{Ra})=10^{3}$ to 0.4 for $(\mathrm{Ra})=10^{6}$.

Fig. 5. Shows the variation of average Nusselt number $(\mathrm{Nu})$ along the hot wall with solid volume fractions for different value of Rayleigh numbers. The result presented in terms of five value of baffle angles $(\varnothing=30,60,90$, 120 , and 150$)$. For all values of (Ra), the average Nusselt number $(\mathrm{Nu})$ was found high for the cases using nanofluid, comparing with the cases using pure fluid and that happens due to enhanced in thermal conductivity. In general, the average Nusselt number is increased when the nanoparticle volume fraction increases. Also, as Rayleigh numbers increase the average 
Ra
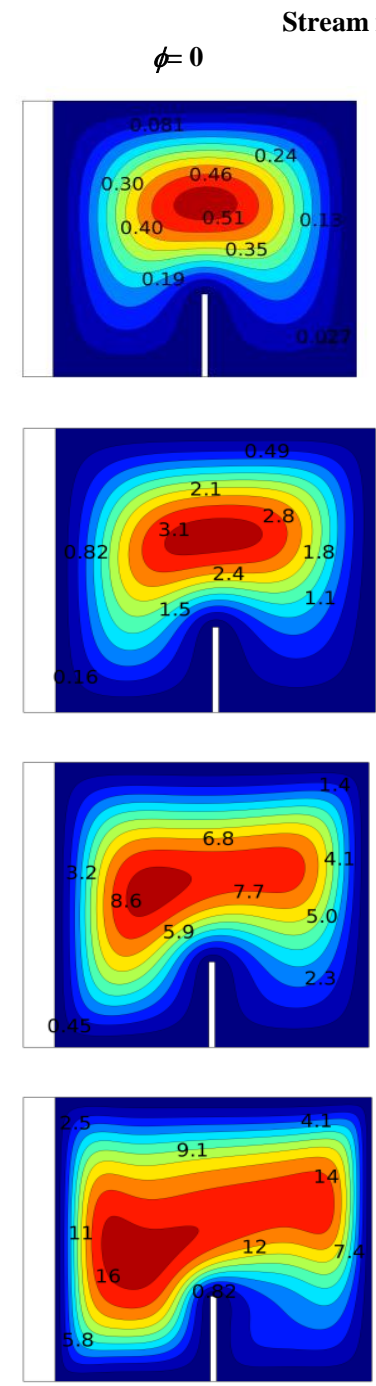

$\phi=0.06$
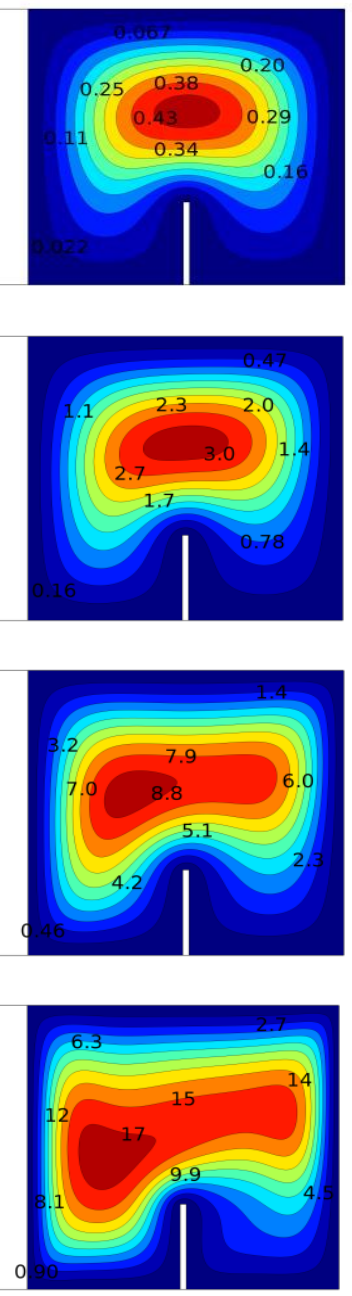
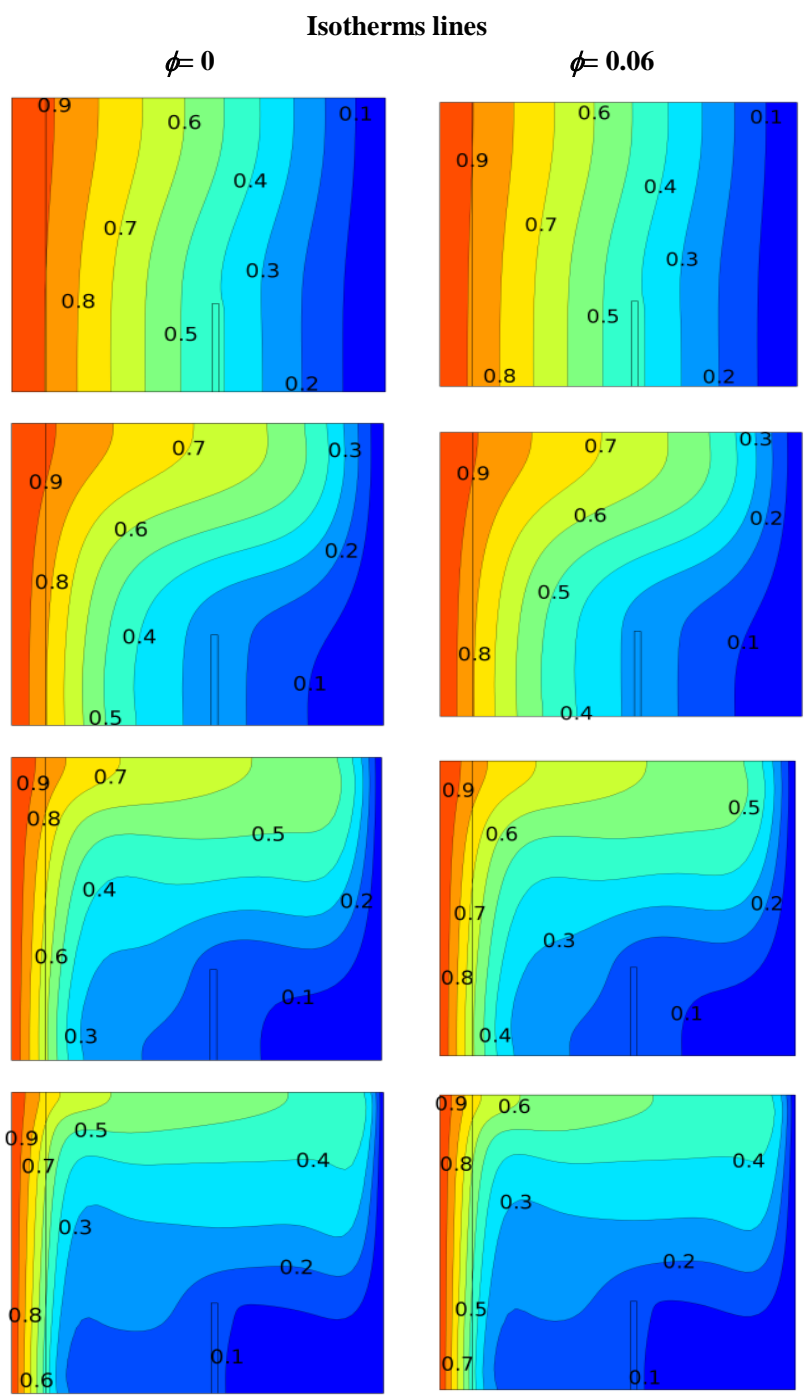

Figure 4. Effect of Rayleigh number on stream function (two left columns) and Isotherms lines (two right columns) for different value of solid volume fraction when $(\mathrm{kr})$ wall $=1, \mathrm{D}=0.2$ and $(\varnothing)=90$

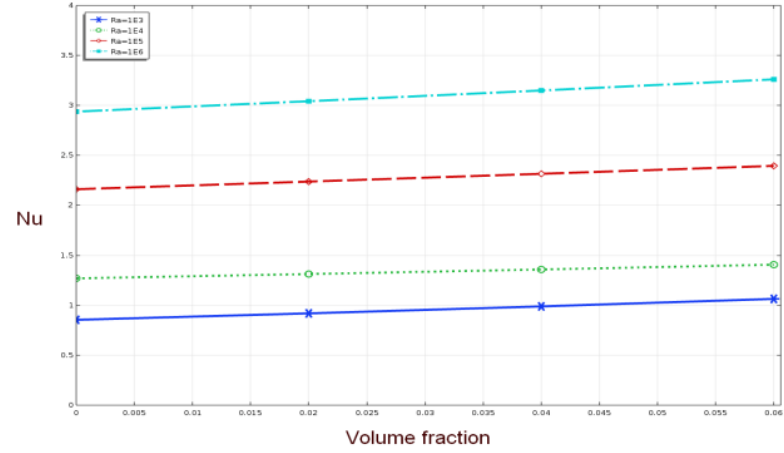

Figure 5. The Average Nusselt number at various Rayleigh number for $(\mathrm{kr})$ wall $=1,(\mathrm{D}=0.2)$ and $(\emptyset=90)$

Nusselt number enhance. At low Rayleigh number (Ra), the effect of nanoparticle presence was more pronounced due to conduction was dominant the heat transfer.

\subsection{Effect of the baffle inclination angle}

In this part, the performance of the enclosure is observed for five baffle's inclination angle (30, 60, 90,120 and 150). Fig. 6. Shows the effects of the baffle inclination angle and solid volume fraction of $\left(\mathrm{Al}_{2} \mathrm{O}_{3}\right.$-water) nanofluid with $(\phi=0.04)$ when $(\mathrm{Kr}=10),(\mathrm{D}=0.3)$ and $\left(\mathrm{Ra}=10^{5}\right)$, on stream function and isotherms contours in the square enclosure. The left two columns show the stream function and the two columns on the right present the isotherm contours in case of pure fluid and nanofluid.

The Left two columns show that circulation cells are formed in the clockwise direction inside the enclosure. This is due to buoyancy effects generate by heating of the left wall of the enclosure. Broadly, the fluid flow within the space is affected by the presence of a fin attached to the lower wall that causes blockage and obstruction of flow near the hot wall, hence the recirculation cores become weak and effect on the buoyant force. As the baffle inclination angle increases from (30 to 60), the flow movement above the baffle is enhanced due to redirects the flow movement and 
strengthening the fluid motion within the area on the left of the baffle. In addition, it can see clearly from the figure that value of stream function increase significantly ( $\psi=9.36$ to 10.6) in this range of angles, in another hand, the maximum value of the stream function can be noticed in case of nanofluid at $(\varnothing=60)$ which equal $(\psi=10.6)$. Whereas they decrease when $(\emptyset>60)$, where the baffle obstruction causing decreases in flow movement, as well as causing a weakening of the recirculating core and buoyant force strength. The stream function values decrease to $(9.2)$ when $(\emptyset=120)$, at this angle value it can be seen that the flow became weak between the baffle and the hot wall as a result of the obstruction that was caused by the baffle. Therefore, the temperature of this area increases which mean there was a decrease in heat transfer rate by the fluid. In addition, the stream function has maximum values located in the center of the recirculation core then progressively reduce. Furthermore, it can be noticed that the position of the primary recirculation core changes with the inclination angle of the baffle. From the right two columns, the figures show that when the inclination angle between $(\varnothing=30$ and 60$)$, the baffle obstruction on flow and fluid resistance are low and leads to increase in the flow movement and buoyancy strength the left side of the baffle. So, the temperature of this region

$\emptyset$
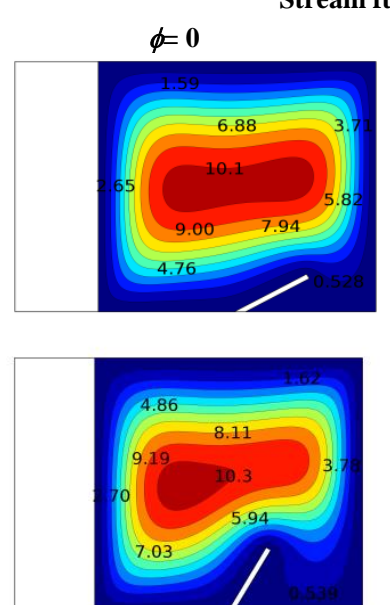

90

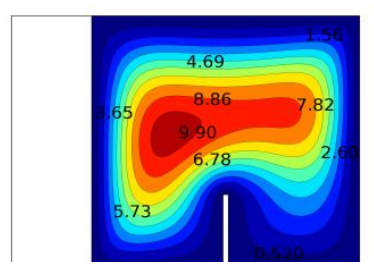

120

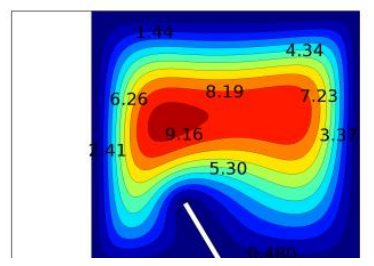

150

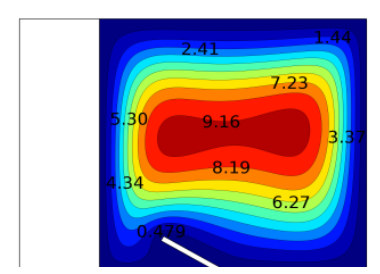

$\phi=0.04$
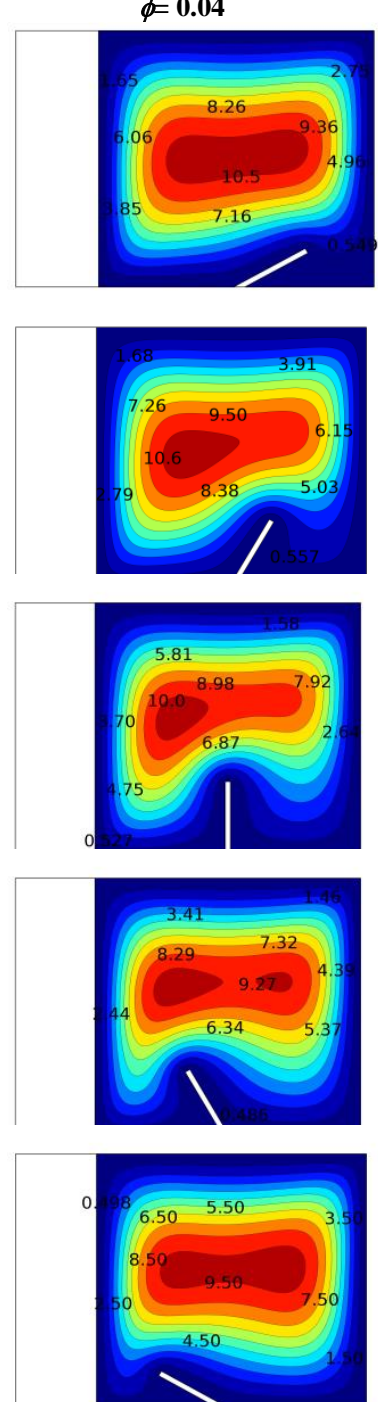

decreases as well as the heat transfer rate through inner fluid enhances. Also, it can be seen that the low levels of temperature are observed near the hot wall (0.3and 0.4 ) as well as the (0.2) level occupies position a little further than the center of the enclosure. That has happened due to the most part of the flow is directed to the solid hot wall of the enclosure. As the inclination angle value raise up to $(\varnothing=90)$, the baffle obstruction on flow and fluid resistance are very high and leads to create a blockage to flow movement close to the wall as seen the (0.2) level. Because of that, the left region temperature increases which cause reduction of the convective heat transfer by the inner fluid temperatures. When the inclination angle increase for more than $(\varnothing>90)$, the baffle obstruction on flow and fluid resistance become smaller, therefore, the buoyancy strength increasing as a result, heat transfer is increasing in this case. It is known that the flow strengths influenced by the presence of nanoparticle when increasing the solid volume fraction, and that happens due to increase the thermal conductivity of the nanofluid, thus improving flow and heat transfer rate through the inner fluid.
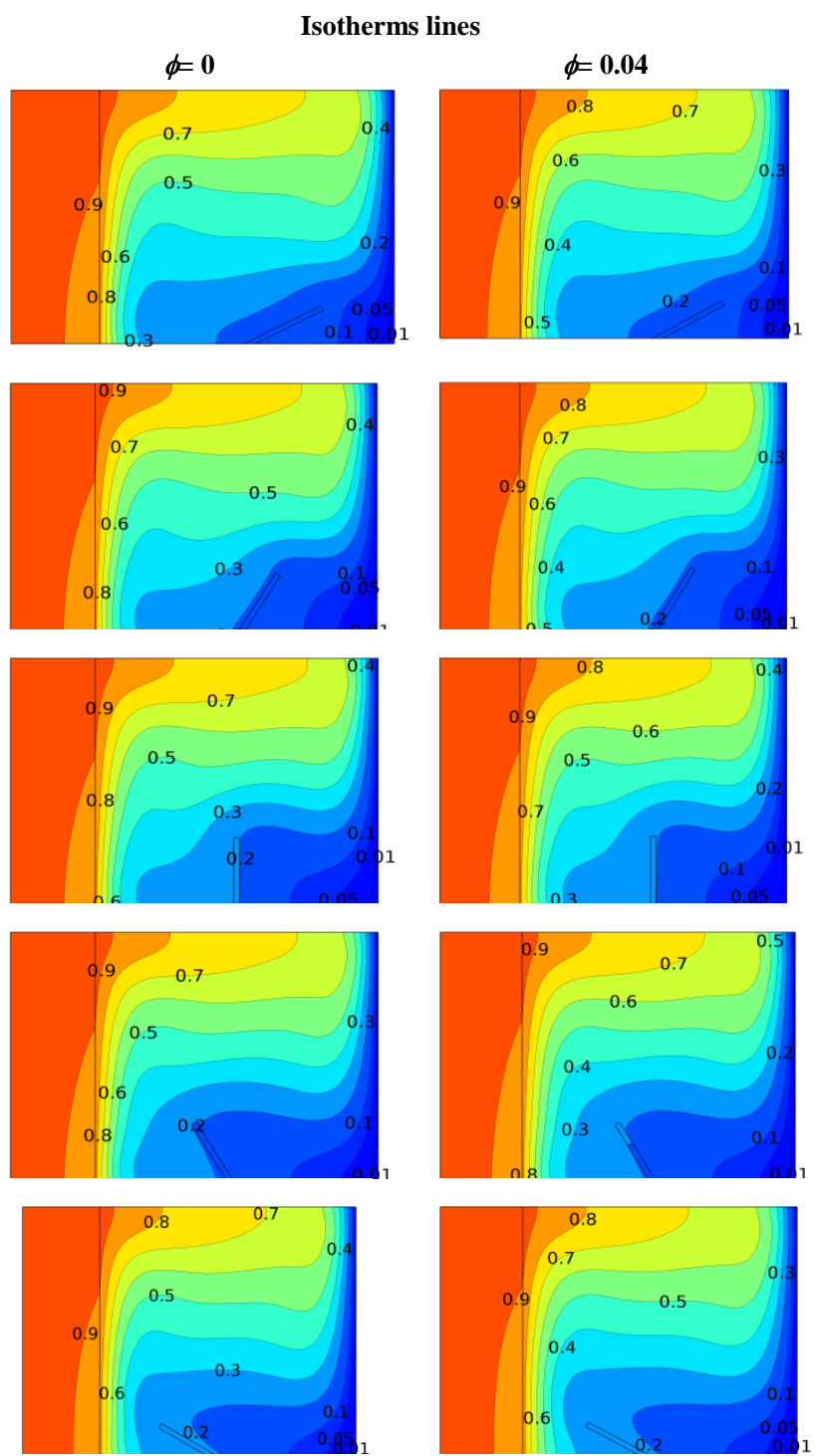

Figure 6. Effect of baffle inclination angle (Ø) on stream function (two left columns) and Isotherms (two right columns) for different value of solid volume fraction when $(\mathrm{Ra})=10^{5}$, wall thickness $(\mathrm{D})=0.3$ and $(\mathrm{kr})$ wall $=10$. 
Fig. 7. Shows the influence of the baffle inclination angle $(\varnothing)$ on average Nusselt number at the left solid wall for the various value of solid particles volume fractions. In general, the tilt angle of the baffle has serious effects on the value of the average Nusselt number. From the figure it can be seen, the higher value of average Nusselt number occurs at $(\varnothing=30)$ in case of the nanofluid and its equal to $(\mathrm{Nu}=2.3)$ compared to the pure fluid. That was happened because of the smallest effect of the baffle obstruction on the flow so that the strength of stream function and the buoyant force still high. Further increasing in $(\varnothing)$, leads to reducing in the average Nusselt number. The increase in the baffle obstruction causing decrease the heat transfer rate due to the reducing in the flow strength. So there will be a decrease in the average Nusselt number clearly have a minimum value equal to $(\mathrm{Nu}=2.18)$ when $(\varnothing=90)$. Furthermore, as the volume fraction of the nanoparticles increases, the average Nusselt number as well as heat transfer rate through inner fluid increases, and the higher effective was found in case of nanofluid equal $(\phi=0.06)$.

\subsection{Effect of the thermal conductivity ratio}

Fig. 8. Shows the solid wall thermal conductivity ratio effect and solid volume fraction for $\left(\mathrm{Al}_{2} \mathrm{O}_{3}\right.$-water) nanofluid at $\left(\mathrm{Ra}=10^{4}, \mathrm{D}=0.1\right.$, and $\varnothing$ $=90$ ) on fluid flow and heat transfer. In general, thermal conductivity ratio means the thermal conductivity ratio of the solid to the thermal conductivity of the fluids , at a low wall conductivity ratio means that the wall thermal resistance is high, so the isotherm lines are parallel to the vertical across the wall, which gives evidence that the conduction heat transferred to the inner fluid is small. It can be observed that an increase in the value of (kr) means raising the solid wall thermal conductivity as a consequence, more heat flux diffuse to the inner fluid by the wall. When increasing the ratio of thermal conductivity $(\mathrm{kr}=0.1$ to $\mathrm{kr}=10)$ the solid wall reflect more heat within the enclosure which presented in distributions of isotherms counter. Also, the maximum magnitude of stream function increases for all rang of solid volume fraction. In the case of $(\mathrm{Kr}=0.1)$, there was a decrease in the amount of heat that passed through the thick wall to the inner fluid, which can be observed through the isothermal line and it was dense inside the wall and parallel to the vertical walls of the space. Because of increasing the thermal conductivity to $(\mathrm{kr}=10)$, the amount of heat transferred through the solid wall to the internal fluid increased. These effects can be seen in the isothermal lines too. It is growth and increases in the temperature gradient, especially in the interface between the solid and the fluid, where the effect of thermal conductivity is very clear in this area.

Fig. 9. demonstrates the variations of the average Nusselt number with the thermal conductivity ratio for different value of solid volume fraction $\left(\mathrm{Al}_{2} \mathrm{O}_{3}\right.$-water) nanofluid and Rayleigh number equal to $\left(\mathrm{Ra}=10^{4}\right)$ and baffle's inclination angle $(\varnothing=90)$. As previously explained, the increase in the volume fraction $(\phi)$ of nanoparticles leads to an improvement in thermal properties, so that the heat transfer by fluid enhance and flow strength in the fluid region improve.

\subsection{Solid Wall Thickness Effect}

The influence of wall thickness on stream function and isotherms counters was observed for dimension range $(\mathrm{D}=0.1,0.2,0.3$ and 0.4). Fig. 10. Shows the effect of the solid wall thickness (D) and solid volume fraction for $\left(\mathrm{Al}_{2} \mathrm{O}_{3}\right.$-water) nanofluid when Rayleigh number $\left(\mathrm{Ra}=10^{4}\right)$, the ratio of thermal conductivity for solid wall $(\mathrm{Kr}=10)$, and the baffle inclination angle $(\varnothing=90)$ on convection heat transfer and fluid flow region.

From the Left two columns, it can be seen the circulation cells of stream function are formed in the clockwise direction. It is known that solid wall thickness (D) has a significant effect on fluid flow and intensive heating to the inner fluid inside the enclosure. It can be noticed that increasing the thickness parameter from $(\mathrm{D}=0.1$ to 0.4$)$ leads to reduce the intensive heating through the solid wall as a result, the stream function decreases from $\psi=21.2$ to $\psi=19.4$ in case of nanofluid. This is because the flow circulation strength decreases as the wall thickness increases. Also, buoyancy force and natural convection inside the enclosure reduced. The right two columns show the isotherms counters and the effect of the solid wall thickness on the temperature distribution within the enclosure. It can be seen that increasing the thickness of the solid wall leads to increased thermal resistance, this because it is directly proportional to wall thickness, causing poor heat transfer to the inner fluid. Also show, an increase in thickness (D) from $D=0.1$ to 0.4 , this leads to reduce the intensive heating through the solid wall and the temperature of this region decreases from 0.9 to 0.7 as well as heat transfer rate through inner fluid become less. In addition, there was a lowering of the average Nusselt number and fluid flow.

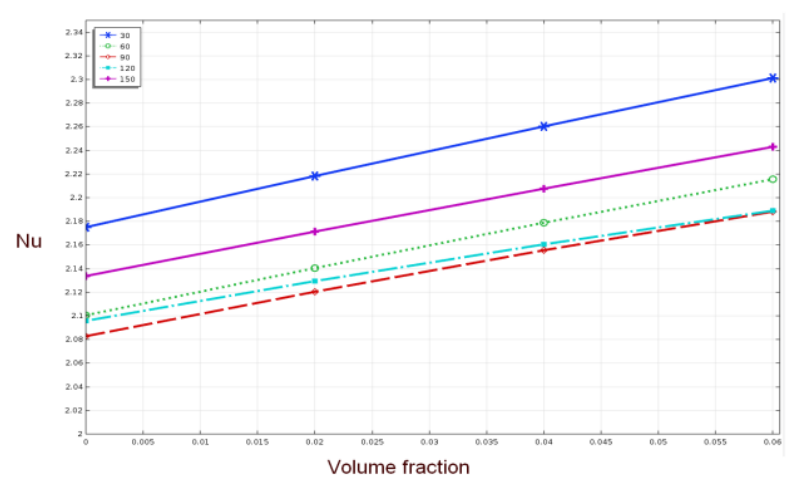

Figure 7. Average Nusselt number with volume fraction at various baffle inclination angle $(\emptyset)$ for $(\mathrm{Ra})=10^{5}, \mathrm{D}=\mathbf{0 . 2}$ and $(\mathrm{kr})$ wall $=10$.

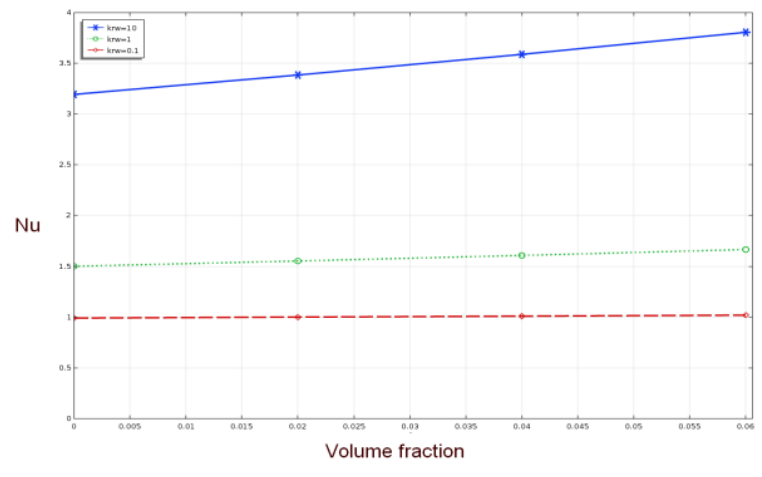

Figure 9. Average Nusselt number with volume fraction at various thermal conductivity ratio for $(\mathrm{Ra})=10^{4}$, and $\emptyset=90^{\circ}$. 
(Kr)

wall

0.1

1

10
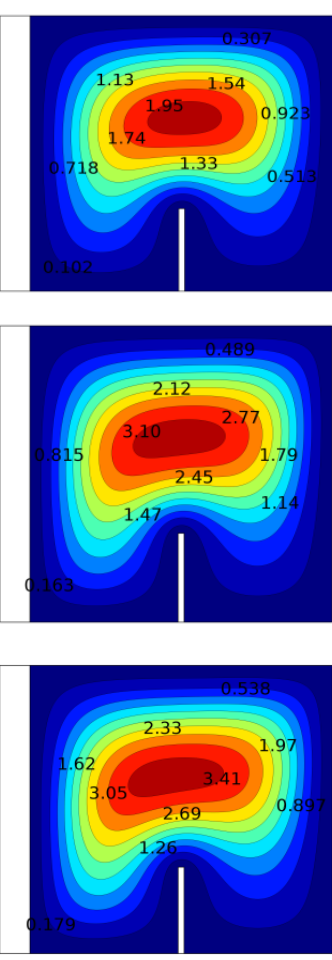

Stream function
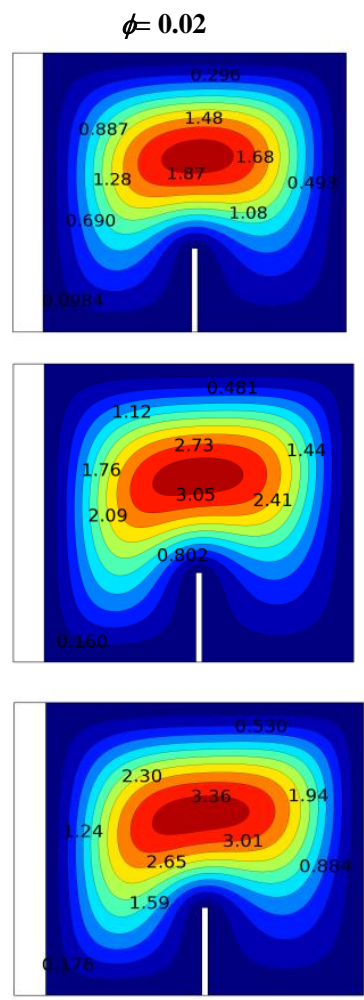

Isotherms lines
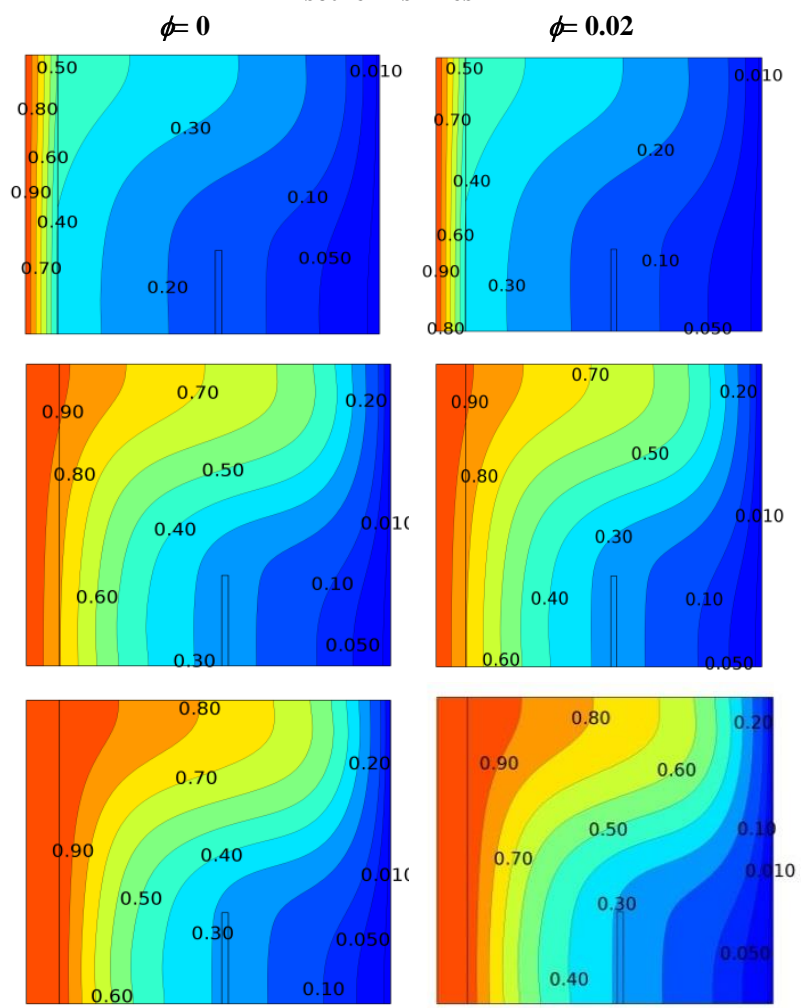

Figure 8. Effect $(\mathrm{Kr})$ of the hot thick wall on stream function (two left columns) and Isotherms (two right columns) for different value of solid volume fraction when $(\mathbf{R a})=10^{4}$ and $(\varnothing)=90$.

D

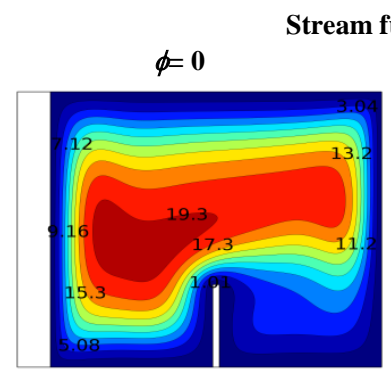

\section{ion}

$\phi=0.06$
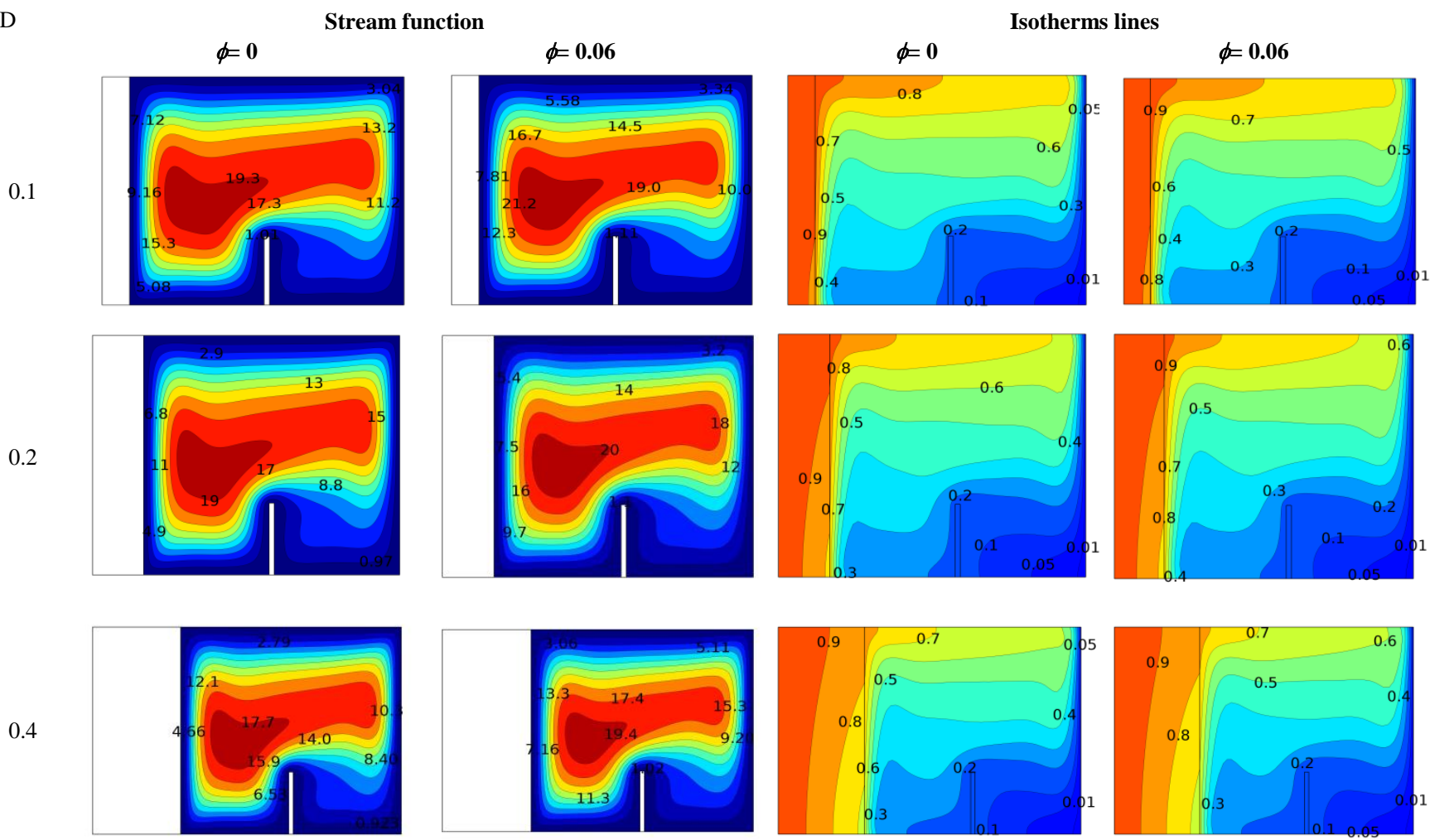

Figure 10. Effect of Solid Wall Thickness (D) on stream function (two left columns) and Isotherms (two right columns) for different value of solid volume fraction when $(\mathrm{Ra})=10^{6}(\mathrm{Kr})$ wall $=10$, and $(\emptyset)=90$. 
Fig. 11. Shows the average Nusselt number variations with the wall thickness and volume fraction of nanoparticles for $\left(\mathrm{Al}_{2} \mathrm{O}_{3}\right.$-water $)$ nanofluid at Rayleigh number $\left(\mathrm{Ra}=10^{6}\right)$ and baffle's inclination angle $(\varnothing=90)$. As shown above, an increase in solid volume fraction $(\phi)$ leads to the heat transfer enhancement, but the thermal resistance of the solid wall is increased when increasing in the solid wall thickness (D) leads to decrease the average Nusselt number( $\mathrm{Nu})$.

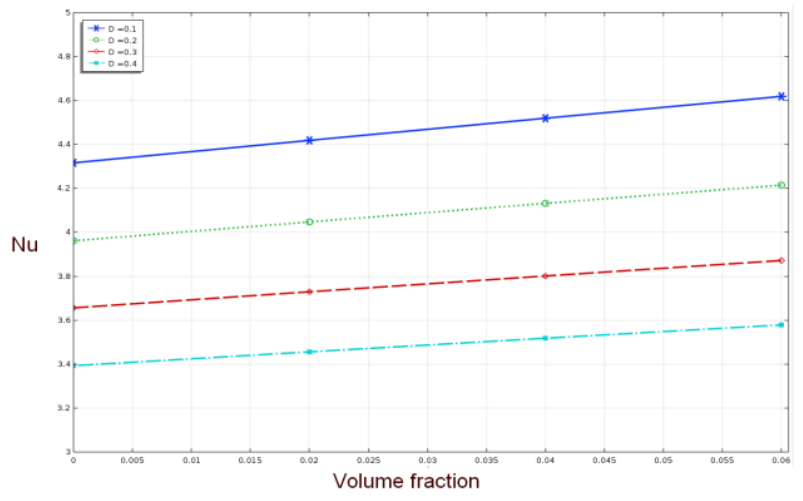

Figure 11. Average Nusselt number at various thick wall thickness (D) when $(\mathrm{Ra})=10^{6},(\mathrm{Kr})=10$ and $(\varnothing)=90$

\section{Conclusion}

In this paper, a numerical investigation is made to study the effect of the inclination angle of the baffle on the performance of natural convection heat transfer and fluid flow within an enclosure with different solid particles concentrations of $\left(\mathrm{Al}_{2} \mathrm{O}_{3}\right)$ and used water at constant properties as base fluid. From the results, it can be concluded that:

- The buoyancy force strength increases and the flow within the cavity is enhanced as Rayleigh number increases. The circulation cell associates with nanofluid are stronger compared with pure water at high Rayleigh numbers.

- The nanoparticles are capable to increase the heat transfer capacity of the base fluid. As solid volume fraction increases, the effect is more noticeable and the thermal performance is enhanced.

- When the baffle angle gets closer to the range of (30-60), the heat transfer is enhanced because the baffle obstruction on flow and fluid resistance is low which leads to increase in the flow movement and buoyancy strength the left side of the baffle. So, the temperature of this region decreases as well as the heat transfer rate through inner fluid enhances.

- The average Nusselt number increases by increasing the Rayleigh number and thermal conductivity ratio as the heat transfer between the wall and fluid on the solid-fluid interface is increased.

- The convection heat transfer inside the cavity filled with nanofluid decreases when extending the thickness of its wall. Therefore, it can be said that the circulation patterns strength can be controlled by the solid wall thickness.

\section{REFERENCES}

[1] S.U.S. Choi, J.A. Eastman, Enhancing thermal conductivity of fluids with nanoparticles, in, United States, 1995.

[2] G. de Vahl Davis, Natural convection of air in a square cavity: a bench mark numerical solution, International Journal for numerical methods in fluids, 3(3) (1983) 249-264.

[3] W. Wu, C.Y. Ching, Laminar natural convection in an air-filled square cavity with partitions on the top wall, in, American Society of Mechanical Engineers, pp. $399-414$

[4] M. Sankar, Y. Do, Numerical simulation of free convection heat transfer in a vertical annular cavity with discrete heating, International Communications in Heat and Mass Transfer, 37(6) (2010) 600-606.

[5] Y. Varol, H.F. Oztop, A. Koca, Effects of inclination angle on conduction — natural convection in divided enclosures filled with different fluids, International Communications in Heat and Mass Transfer, 37(2) (2010) 182-191.

[6] A.K. Santra, S. Sen, N. Chakraborty, Study of heat transfer augmentation in a differentially heated square cavity using copper-water nanofluid, International Journal of Thermal Sciences, 47(9) (2008) 1113-1122.

[7] E. Abu-Nada, H.F. Oztop, Effects of inclination angle on natural convection in enclosures filled with $\mathrm{Cu}$-water nanofluid, International Journal of Heat and Fluid Flow, 30(4) (2009) 669-678.

[8] K.C. Lin, A. Violi, Natural convection heat transfer of nanofluids in a vertical cavity: Effects of non-uniform particle diameter and temperature on thermal conductivity, International Journal of Heat and Fluid Flow, 31(2) (2010) 236245.

[9] C.J. Ho, W.K. Liu, Y.S. Chang, C.C. Lin, Natural convection heat transfer of alumina-water nanofluid in vertical square enclosures: An experimental study, International Journal of Thermal Sciences, 49(8) (2010) 1345-1353.

[10] G.A. Sheikhzadeh, A. Arefmanesh, M.H. Kheirkhah, R. Abdollahi, Natural convection of $\mathrm{Cu}$-water nanofluid in a cavity with partially active side walls, European Journal of Mechanics - B/Fluids, 30(2) (2011) 166-176.

[11] P. Ternik, R. Rudolf, Heat transfer enhancement for natural convection flow of water-based nanofluids in a square enclosure, International Journal of Simulation Modelling, 11(1) (2012) 29-39.

[12] T. Basak, A.J. Chamkha, Heatline analysis on natural convection for nanofluids confined within square cavities with various thermal boundary conditions, International Journal of Heat and Mass Transfer, 55(21) (2012) 5526-5543.

[13] M. Cianfrini, M. Corcione, A. Quintino, Natural convection in square enclosures differentially heated at sides using alumina-water nanofluids with temperaturedependent physical properties, Thermal Science, 19(2) (2015) 591-608.

[14] G.S.a.J.M.K. Xundan Shi, Professor, Laminar Natural Convection Heat Transfer in a Differentially Heated Square Cavity Due to a Thin Fin on the Hot Wall, Journal of Heat Transfer, 125 (2003) 624 - 634.

[15] S. Humaira Tasnim, M.R. Collins, NUMERICAL ANALYSIS OF HEAT TRANSFER IN A SQUARE CAVITY WITH A BAFFLE ON THE HOT WALL, International Communications in Heat and Mass Transfer, 31(5) (2004) 639-650.

[16] E. Bilgen, Natural convection in cavities with a thin fin on the hot wall, International Journal of Heat and Mass Transfer, 48(17) (2005) 3493-3505.

[17] H. Oztop, E. Bilgen, Natural convection in differentially heated and partially divided square cavities with internal heat generation, International journal of heat and fluid flow, 27(3) (2006) 466-475.

[18] H. Ambarita, K. Kishinami, M. Daimaruya, T. Saitoh, H. Takahashi, J. Suzuki, Laminar natural convection heat transfer in an air filled square cavity with two insulated baffles attached to its horizontal walls, Thermal science and engineering, 14(3) (2006) 35-46.

[19] A. Ben-Nakhi, A.J. Chamkha, EFFECT OF LENGTH AND INCLINATION OF A THIN FIN ON NATURAL CONVECTION IN A SQUARE ENCLOSURE, Numerical Heat Transfer, Part A: Applications, 50(4) (2006) 381-399. 
[20] M. Ghassemi, M. Pirmohammadi, G.H. Sheikhzadeh, A.,'A Numerical Study of Natural Convection in a Tilted Cavity with Two Baffles Attached to its Isothermal Walls', WSEAS Transactions on Fluid Mechanics, 2(3) (2007) 61-68.

[21] G. Nardini, M. Paroncini, R. Vitali, Natural convection in a square cavity with two baffles on the vertical walls: experimental and numerical investigation.

[22] G.A. Sheikhzadeh, M. Pirmohammadi, M. Ghassemi, A numerical study of natural convection in a cavity with two fins attached to its vertical walls, in, American Society of Mechanical Engineers, pp. 453-460.

[23] A. Elatar, M.A. Teamah, M.A. Hassab, Numerical study of laminar natural convection inside square enclosure with single horizontal fin, International Journal of Thermal Sciences, 99 (2016) 41-51.

[24] M. Torabi, A. Keyhani, G.P. Peterson, A comprehensive investigation of natural convection inside a partially differentially heated cavity with a thin fin using twoset lattice Boltzmann distribution functions, International Journal of Heat and Mass Transfer, 115 (2017) 264-277.

[25] A.H. Mahmoudi, M. Shahi, A.H. Raouf, A. Ghasemian, Numerical study of natural convection cooling of horizontal heat source mounted in a square cavity filled with nanofluid, International Communications in Heat and Mass Transfer, 37(8) (2010) 1135-1141.

[26] A. Habibzadeh, H. Sayehvand, A. Mekanik, Numerical study of natural convection in a partitioned square cavity filled with nanofluid, International Journal of Chemical Engineering and Applications, 2(4) (2011) 261.

[27] H. Sayehvand, A. Habibzadeh, A. Mekanik, CFD analysis of natural convection heat transfer in a square cavity with partitions utilizing $\mathrm{Al} 2 \mathrm{O} 3$ nanofluid, International Journal of Nano Dimension, 2(3) (2012) 191-200.

[28] Y. Naoufal, M. Zaydan, S. Rachid, Numerical study of natural convection in a square cavity with partitions utilizing $\mathrm{Cu}$-Water nanofluid, International Journal of Innovative Research in Science, Engineering and Technology, 4 (2015) 10354-
10367.

[29] F. Selimefendigil, H.F. Öztop, Conjugate natural convection in a cavity with a conductive partition and filled with different nanofluids on different sides of the partition, Journal of Molecular Liquids, 216 (2016) 67-77.

[30] V.A.F. Costa, M.S.A. Oliveira, A.C.M. Sousa, Control of laminar natural convection in differentially heated square enclosures using solid inserts at the corners, International journal of Heat and Mass transfer, 46(18) (2003) 3529 3537.

[31] M. Mobedi, Conjugate natural convection in a square cavity with finite thickness horizontal walls, International Communications in Heat and Mass Transfer, 35(4) (2008) 503-513.

[32] T. Basak, R. Anandalakshmi, A. Kumar Singh, Heatline analysis on thermal management with conjugate natural convection in a square cavity, Chemical Engineering Science, 93 (2013) 67-90.

[33] A.I. Alsabery, A.J. Chamkha, H. Saleh, I. Hashim, Heatline visualization of conjugate natural convection in a square cavity filled with nanofluid with sinusoidal temperature variations on both horizontal walls, International Journal of Heat and Mass Transfer, 100 (2016) 835-850.

[34] A.J. Chamkha, M.A. Ismael, Conjugate heat transfer in a porous cavity filled with nanofluids and heated by a triangular thick wall, International Journal of Thermal Sciences, 67 (2013) 135-151.

[35] A. Abdulkadhim, A.M. Abed, K. Al-Farhany, Computational investigation of conjugate heat transfer in cavity filled with saturated porous media, Frontiers in Heat and Mass Transfer, 11 (2018).

[36] M.A.A. Ishrat Zahan, Effect of conjugate heat transfer on flow of nanofluid in a rectangular enclosure, International Journal of Heat and Technology, 36 (2018) 8 . 